\title{
VULNERABILITY ANALYSIS FOR TWO ACCIDENT SCENARIOS AT AN UPPER-TIER SEVESO ESTABLISHMENT IN ROMANIA
}

\author{
Lucrina ŞTEF $\breve{A N E S C U} U^{1}$, Camelia BOTEZAN ${ }^{1 *}$, Iulia CR $\breve{A C I U N} N^{1}$
}

DOI: 10.21163/GT_2018.131.10

\begin{abstract}
:
Major accidents involving dangerous substances pose a serious threat to the health and safety of local communities and the environment, as well as to the integrity and development of infrastructure where Seveso establishments are located. In some cases, the disastrous effects may affect larger, even cross-border areas. At European level, there are continuous efforts to develop land-use planning policies and regulations to reduce consequences and to prevent future accidents from happening. Hence, research in this field comes to support the current actions and strategies of the European Commission to improve the capacity of the EU Member States to cope with and respond to the identified risks through effective prevention, preparedness and response measures. In Romania, the Seveso establishments are mostly located in or very close to urban areas. This paper analyses vulnerability in case of two different accident scenarios (explosion and toxic dispersion) in Targu-Mures, a city hosting one of the largest Seveso upper-tier establishments in Romania. The approach starts with exposure analysis - the first step in the process of vulnerability analysis - which identifies all the elements at risk, be they social (population, medical facilities, schools), environmental (protected areas, water bodies) or economic (transport infrastructure, buildings, utility and water supply networks, fuel or food storage facilities). Following the exposure analysis, vulnerability is assessed based on indicators selected in such way so that they cover the entire range of social, economic, environmental aspects, as well as the existing response capabilities in case of a major accident.
\end{abstract}

Key-words: vulnerability, exposure, Seveso establishments, dangerous substances, chemical accident.

\section{INTRODUCTION}

Risks induced by human activities increased proportionally to the development of industrial facilities. Disasters occurring in highly populated urban areas may be caused by various factors, from human error to equipment failure and natural events such as earthquakes, tornadoes, floods, tsunamis (the so-called NaTech events - Natural Hazard Triggering Technological Disasters) (Ruffi et al., 2017; Campedel, 2008).

Urban vulnerability has been defined as the liability of a city and its infrastructure to losses caused by disasters (Karashima et al., 2014). The urbanization and industrialization processes have led to increased exposure and risks, causing also significant changes in land cover and land-use. Smith (1992) lists among the reasons of increasing trends in disaster consequences: population growth, land pressure, economic growth, technological innovation, social expectations and growing interdependence of individuals, communities

\footnotetext{
${ }^{1}$ Babeş-Bolyai University, Faculty of Environmental Science and Engineering, Research Institute for Sustainability and Disaster Management based on High Performance Computing - ISUMADECIP, 30 Fantanele, Cluj-Napoca, Romania, *Corresponding author: camelia.costan@ubbcluj.ro.
} 
and nations. Hence, these reasons are also at the foundation of increased vulnerability of urban communities.

Exposure is a component of disaster risk, together with vulnerability and hazard. The exposure, as a component of vulnerability, has a dynamic character, varying in both temporal and spatial scale (Botezan et al., 2015). It depends on a number of factors: economic, social, geographic, demographic, cultural or institutional. The lack of resilience and the ability to anticipate and adapt to extreme events are also important causal factors of exposure (Cardona, 2012). A high level of exposure is often the result of a distorted development process, such as the one associated with poor environmental management, demographic changes, rapid and unplanned urbanization, and limited life options for the poor people.

Several legislative instruments, especially the Seveso II Directive 96/82/EC with its amendment, Directive 2003/105/EC, and the SevesoIII (Directive 2012/18/EU) are already in force, with the specific aim of preventing and reducing the number of accidents and their consequences. The directives were named after the small town of Seveso, north of Milan, Italy, where an industrial accident occurred at the local chemical manufacturing plant on the $10^{\text {th }}$ of July 1976. Accidents as those in Seveso (1976), Bhopal (1984), Enschede (2000) and Toulouse (2001) have clearly shown that the consequences of technological accidents can be amplified by the proximity of Seveso facilities to residential and highly populated areas (Christou, 2011; Li et al., 2010). As a consequence, the European legislation required major changes, which referred to the introduction of provisions related to land-use planning (Török et al., 2011). These legal instruments set safe distances for the building of new industrial facilities, separated from residential and commercial areas. These distances should be long enough to ensure the safety of the human population and the environment. Also, the established distance will depend on the vulnerability of the exposed community and on the risk level (facility type, dangerous substances involved, management systems etc.) (Cozzani et al., 2006). For example, it is expected that buildings where more vulnerable people spend their time, such as schools and hospitals, are located in safer areas, away from industrial areas. However, although land-use planning measures and transportation regulations are in place, including by the SevesoIII Directive, there are some old Seveso sites which are dangerously close to crowded places, like shopping malls, which is also the case of the current example.

\section{CASE STUDY AND SCENARIOS}

The case study chosen for this research is located in Targu Mures, Transylvania (Fig. 1). It is an important urban center and the county seat of Mures. The city experienced significant economic and social development, having in 2011 a population of 134,290 inhabitants. The analyzed Seveso site is the chemical plant in the western industrial area of Targu Mures, $4 \mathrm{~km}$ away from the city center and close to the European road E60 where a big shopping mall is located. From a geographical point of view, the chemical plant is located in the valley corridor of Mures, delimited in the North by the Transylvanian Plain and in the South by Madarasului Hills, included in the Tarnavelor Plateau.

The two types of hazards associated with the site are toxic ammonia dispersion and overpressure explosion of ammonium nitrate. In the first case, the potential amount involved is 15,000 tones, which might affect about 183,551 people in the hazard area.

Scenario 1: Massive discharge of ammonia in this industrial site may occur due to a severe damage caused by one of the following: 
- earthquake or other natural disasters that may compromise the structural integrity of the tank storing the ammonia, followed by loss-of-containment (the Natech event);

- human error of operation due to failure to comply with the rules on technological workflow by exceeding the temperature and the pressure of the workflow;

- technological and mechanical damages;

- $\quad$ armed attack (military or terrorist);

- falling large objects in the atmosphere (airplane, meteorite);

- diversion/sabotage.

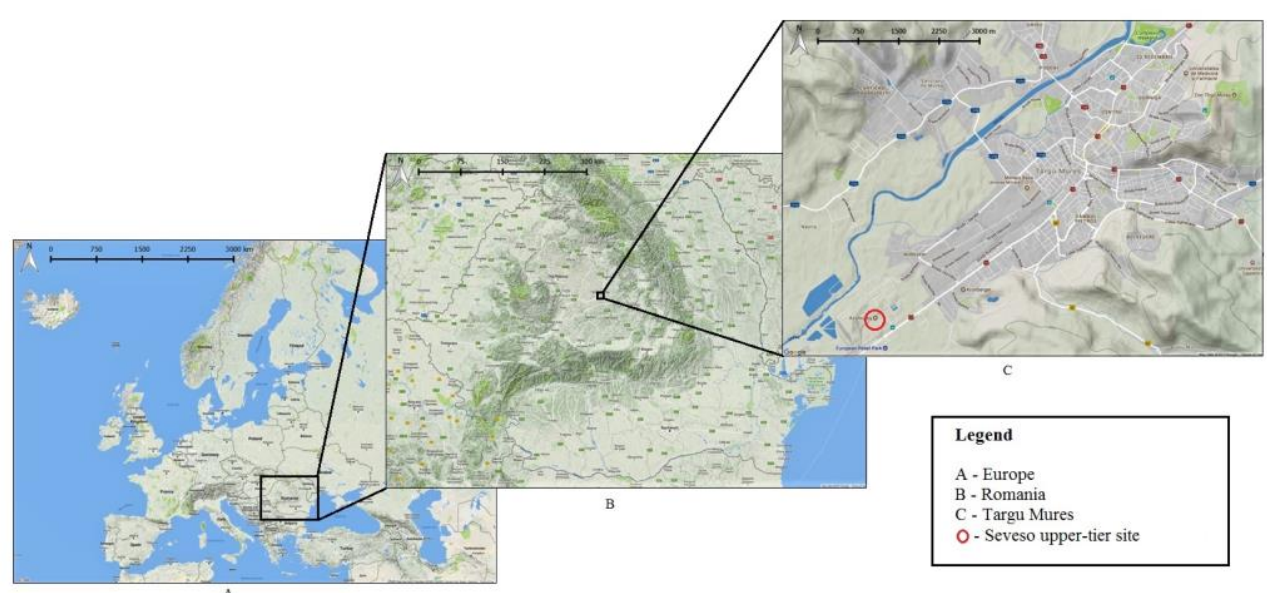

Fig. 1 Location of the study area.

The impact area with toxic dispersion depends on the weather conditions, and under unfavorable conditions it can extend over a radius of $10 \mathrm{~km}$. Regarding the temporal position, the event can occur at any time of the day during the system operation and the duration of toxic effect depends in particular on the conditions of the toxic cloud formation (weather conditions, topography and roughness of the terrain).

Scenario 2: The second type of hazard - the overpressure explosion - can occur in the ammonium nitrate storage facility at the same chemical plant. This storage facility is located on the right bank of the Mures River and the number of inhabitants in the hazard area is 5,942. Considering that in the case of this hazard there is an explosion with overpressure, the transport ( $2.15 \mathrm{~km}$ of the E60 European road), public utilities (1 pumping station) and economical (Promenada Mall and 1 food store) infrastructure will be affected and their activity will be interrupted immediately.

The explosion of the ammonium nitrate packed in bags may be caused by one of the following:

- explosion in the neighborhood of the storage facility, leading to the explosion of the ammonium nitrate due to the resulting shock wave (Domino effect);

- fire in the neighborhood of the storage facility which might cause the Domino effect;

- human error due to failure to comply with the rules on handling the dangerous substances;

- $\quad$ armed attack (military or terrorist);

- large falling objects in the atmosphere (airplane, meteorite);

- diversion/sabotage. 
The event can occur at any time of the day during the plant operation. In terms of duration, the explosion of the ammonium nitrate can occur suddenly if the cause of the explosion is another explosion produced in the neighborhood or it can last tens of minutes if the cause of the explosion is a fire burst inside the plant. The explosion of ammonium nitrate itself occurs suddenly and the effects are immediate, but the event may continue for a period of time that may take a few days, until the liquidation of the other events (fires/explosions, toxic dispersions) which a massive explosion at a fertilizer plant can generate through the Domino effect.

\section{METHODOLOGY}

\subsection{Exposure analysis}

In recent years, several attempts have been made to define and establish exposure assessment methodologies. Particular attention has been paid to the exposure of population and environment to chemical hazards and to the impact of these hazards on the mentioned components. Regarding the environmental risks, the exposure assessment is based on the characterization of the geophysical processes inducing the risks, including the magnitude, frequency, spatial dispersion, duration, rate of onset, time, and temporal spacing of physical conditions.

In order to assess the exposure of social factors, the number of inhabitants from the Territorial Administrative Units (TAUs) included in the scenarios was identified, respectively the estimated number of inhabitants in the hazard-prone area. The number of inhabitants in the hazard-prone area was estimated based on the density of population in the built-up area.

The surface of the residential areas in the hazard-prone area was also analyzed. This was weighted against the total surface of residential areas within the TAU contained in the buffer, using the GIS technique. A distinction has been made between residential areas where buildings were destroyed by explosion and the affected residential areas with no infrastructure destroyed by the toxic dispersion. The capacity of medical and educational units (the number of hospital beds, primary schools and high schools) was analyzed.

In order to assess the relevant environmental factors exposure, the rivers and the lakes (the areas obtained from the CORINE LAND COVER 2012 database) were analyzed, together with the protected natural areas designated according to the Habitats Directive (Sites of Community Importance - SCI and Avifaunistic Special Protection Areas - SPAs) in the hazard-prone area. The length of the rivers in the hazard area was determined and the areas of the lakes in the hazard-prone area were calculated. The protected areas located in the hazard-prone area have been weighted both against their surface within the TAU and against the total extent of the protected area. Their possible overlaps were also taken into account (SCI overlapping SPAs); in the end only one territorial footprint was considered.

In order to assess the exposure of economic components, the industrial sites, transport infrastructure, public utilities networks, drinking water supply networks and fuel, food and consumer goods warehouses were analyzed. In the case of industrial areas, their surface in the hazard area was analyzed against the total surface of the industrial areas within the TAUs contained in the buffer using the GIS technique. In the case of the transport infrastructure, the airports in the hazard area, as well as the transport routes were analyzed, their length being identified in the hazard-prone area. Concerning the public utility networks, their presence in the hazard-prone area and the possibility of their destruction due to explosions were analyzed. The power, thermal power, transformer power, gas pressure 
measuring stations and wastewater treatment plants in the hazard-prone area were identified, as well as water catchments and pumping or water treatment stations. Also, the existence of fuel, food and consumer goods warehouses was monitored in the hazard-prone area.

\subsection{Vulnerability analysis}

Urban vulnerability to technological risks has been examined over the years in terms of four distinct factors: 1 . the current pattern of hazardous technologies in relation to urban populations; 2. adequacy of land-use planning and control; 3. effectiveness of emergency planning and response; and 4. the socio-characteristics of the urban population (Liverman, 1986). Hence, these are also translated in a wide range of indicators used in numerous vulnerability assessment methodologies (Knox, 1980; Fedeski \& Gwilliam, 2007; Zabeo et al., 2011; Das et al., 2012; Plummer et al., 2013; Constantin et al., 2015).

The vulnerability analysis is a systematic examination of buildings, utilities, population and economic components in order to identify the characteristics that are susceptible to be damaged by a disaster. In literature, it is considered that, for different categories of elements exposed, different vulnerability indices must be deployed and their average can be considered the vulnerability value of the system. In order to conduct an index-based vulnerability analysis, indicators for each index must be selected (Chuanglin \& Yan, 2016; Lee, 2014; Armaș \& Gavriș, 2016).

In this study, in order to set an index used in the vulnerability ranking of a system, arbitrary values of indicators quantification are determined, each indicator being qualitatively analyzed. The importance of the indicator is determined by its classification into one of the following three levels:

- $\quad$ Lesser importance - it has an indirect influence on the vulnerability - value 1;

- $\quad$ Moderate importance - it has a direct influence on the vulnerability - value 2;

- $\quad$ Great importance - it has a decisive influence on the vulnerability - value 3.

Furthermore, the vulnerability category of the indicator was classified into three levels:

- $\quad$ Low - value 1; Medium - value 2; High - value 3.

The vulnerability analysis was structured into social, economic, physical and environmental components. In this way, the main elements exposed to disaster risk are assessed: population, assets and environmental factors. Moreover, following the analysis of the selected scenarios, two categories of vulnerability indicators have been defined: general (common to all type of hazards) and specific (which characterize the analyzed hazards: accidents at Seveso upper-tier establishments).

The arithmetic mean of the indices values set for each indicator represents the total value of the system vulnerability. This value was furthermore divided into five levels: very low $(0-1.8)$, low $(1.8-3.6)$, medium $(3.6-5.4)$, high $(5.4-7.2)$, and very high $(7.2-9)$ (Chuanglin \& Yan, 2016).

The general indicators (i1-i10) cover the socio-demographic aspects (population density, demographic dependency ratio), the human capital aspects (unemployment rate, Gross Enrollment Ratio - GER, incomes, capacity of medical units, number of physicians per 1,000 inhabitants) and aspects related to physical and ecological vulnerability (hazardous industry, protected areas, water bodies). The data related to socio-demographic indicators were collected from the 2011 population and housing census, except the population density which was calculated by the authors for each particular scenario. For some indicators (population density, total demographic dependency ratio, number of physicians per 1,000 inhabitants) data were available at locality level and, therefore, the 
vulnerability index was calculated also at locality level, i.e. more accurately. For the rest of the vulnerability indicators, statistic data at TAU level were used because data were missing at locality level.

Several studies on social vulnerability (Adger et al., 2004; Cutter et al., 2014; Lee, 2014) use disaster response capacities in their analyses. Of the disaster response capacity indicators, this paper considers the following specific indicators (i11-i16) as crucial: information/awareness campaigns for the population, training activities (exercises, simulations), population alarm systems coverage, existence of emergency shelters correlated to the number of population, existence of special CBRN (Chemical, Biological, Radiological and Nuclear) intervention teams, population endowment with individual protection equipment. These cover all measures of prevention, mitigation, preparedness and response that support the community to cope with and to recover after extreme events. These specific indicators were selected according to hazard type (Seveso accidents) and they were evaluated based on data from the official reports and studies of the county inspectorate for emergency situations.

\section{RESULTS AND DISCUSSION}

\subsection{Exposure analysis}

The exposure to Seveso upper-tier establishment hazards was assessed considering the elements at risk within the hazard-prone area: population, residential areas, sanitary units, educational units, protected natural areas, water bodies, industrial areas, transport infrastructure, public utilities, fuel deposits and large population agglomerations, drinking water supply networks.

The degree of exposure is larger for the first scenario and the exposed elements are affected differently. These differences are generated by the fact that the hazard-prone areas differ from one scenario to another and the two types of hazards are affecting the exposed elements in different ways. Even though the area affected by the toxic dispersion is larger and more elements are exposed and affected, the effects are not as severe as the effects of the explosion which are more direct and have a physical impact. For example, the toxic dispersion can affect $55.33 \%$ of the residential areas, without damaging the infrastructure, while the explosion can affect just $5.06 \%$ of the residential area, but in this case the building infrastructure can be damaged. The results show the same situation when considering the medical and educational units: the toxic dispersion can disturb the activities without affecting the infrastructure (the total number of hospitals in TAU - 16, total number of education units in TAU - 45), while the explosion can damage the infrastructure of these units (however, there are no medical and educational units in the hazard-prone area). The same situation is found in the case of protected natural areas (the surface of the natural area located in the hazard-prone area is $32.89 \mathrm{~km}^{2}$ ). These could be affected only in the case of toxic dispersion as the area affected by explosion does not include protected natural areas.

The industrial areas have a similar exposure percentage for both scenarios $35 \%$ and $22.16 \%$, expressed as ratio between the surfaces of the industrial area located in the hazardprone area/total surface of industrial area in TAU). However, in the case of explosion the infrastructure can be affected. In the case of transport infrastructure, the toxic dispersion can affect the airport activities, while the explosion can damage $2.15 \mathrm{~km}$ of the road.

Based on the assessment of the factors described above, exposure maps have been made for each analyzed scenario (Fig. 2). The maximum radius of hazard-prone area for the 
first scenario was $10,765 \mathrm{~m}$, while for the second scenario it was $941 \mathrm{~m}$ (the radius was calculated based on the most unfavorable weather conditions).

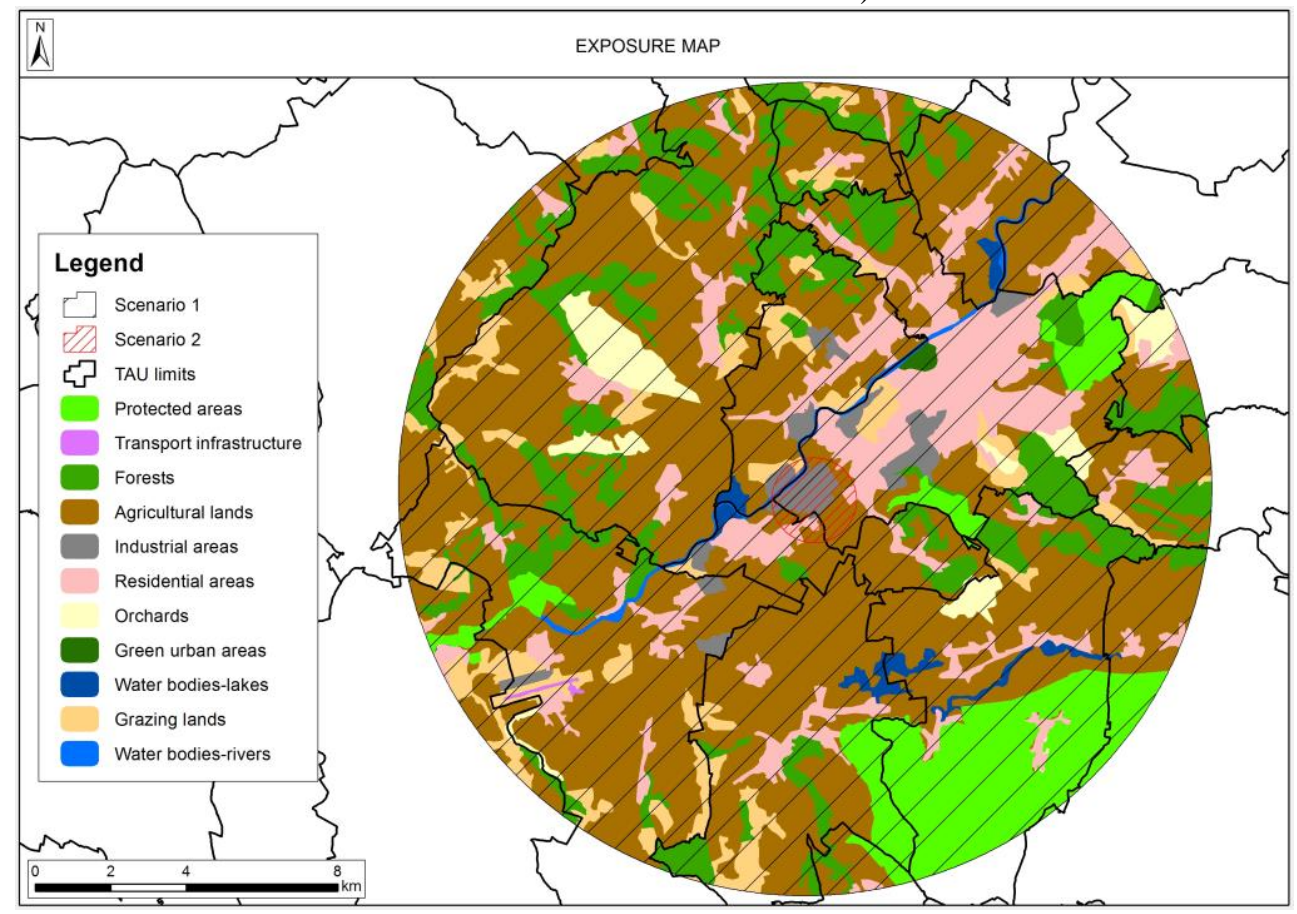

Fig. 2 Exposure map for the two analyzed scenarios

\subsection{Vulnerability analysis}

Following the analysis of selected indicators, the values for the two scenarios were summarized in Table $\mathbf{1 .}$

The total vulnerability index for Scenario 1 - toxic dispersion (ammonia) is 4.8 , and for Scenario 2 - explosion (ammonium nitrate) is 4.3 , both falling under the moderate vulnerability category.

In terms of general indicators analyzed, the two scenarios were assigned similar values in some cases (unemployment rate of $2.68 \%$, capacity of medical units - 19 beds per 1,000 inhabitants, as compared to the average national value of 6.6 beds/1,000 inhabitants). High values were recorded for population density, demographic dependency ratio and average income (lower than the national value). The general indicators that really differentiate the two scenarios are the hazardous industries, natural protected areas and water bodies. In Scenario 1 there are two more other Seveso establishments in the hazard-prone area, leading to a high vulnerability from this point of view. Moreover, 35\% of the protected areas are located in the area of the scenario (moderate vulnerability); while $42.60 \%$ of the water bodies are within the scenario limits (also moderate vulnerability). In the second scenario, the lower vulnerability is given by the lack of other Seveso establishments and lack of natural protected areas and water bodies in hazard-prone area. Campaigns for raising awareness are developed annually in Târgu-Mureș and in the neighboring villages, indicating a low vulnerability level. 
Table 1.

Vulnerability results for the two scenarios.

\begin{tabular}{|c|c|c|c|c|c|c|}
\hline \multirow{2}{*}{$\begin{array}{c}\text { Indica } \\
\text { tor }\end{array}$} & \multirow[t]{2}{*}{ Vulnerability indicator } & \multirow{2}{*}{$\begin{array}{l}\text { Impor } \\
\text { tance }\end{array}$} & \multicolumn{2}{|c|}{ Scenario 1} & \multicolumn{2}{|c|}{ Scenario 2} \\
\hline & & & Category & Total & Category & Total \\
\hline i1. & $\begin{array}{ll}\begin{array}{l}\text { Population } \\
\left(\text { inhab. } / \mathrm{km}^{2}\right)\end{array} & \text { density }\end{array}$ & 3 & $2(250-2000)$ & 6 & $3(>=2000)$ & 9 \\
\hline $\mathrm{i} 2$. & $\begin{array}{l}\text { Demographic dependency } \\
\text { ratio }\end{array}$ & 3 & $3(>40 \%)$ & 9 & $3(>40 \%)$ & 9 \\
\hline i3. & Unemployment rate & 1 & $1(<3 \%)$ & 1 & $1(<3 \%)$ & 1 \\
\hline i4. & $\begin{array}{lll}\begin{array}{l}\text { Gross } \\
(\text { GER })\end{array} & \text { Enrolment } & \text { Ratio } \\
\end{array}$ & 2 & $3(<60 \%)$ & 6 & $2(60-75 \%)$ & 4 \\
\hline $\mathrm{i} 5$. & Average income & 1 & $3(<1800)$ & 3 & $3(<1800)$ & 3 \\
\hline i6. & $\begin{array}{lrr}\text { Capacity of } & \text { medical units } \\
\text { (no. } & \text { of } & \text { beds } / 1,000 \\
\text { inhabitants) } & \end{array}$ & 3 & $1(>10)$ & 3 & $1(>10)$ & 3 \\
\hline i7. & $\begin{array}{l}\text { Number of physicians per } \\
1,000 \text { inhabitants }\end{array}$ & 3 & $3(<1.3)$ & 9 & $\begin{array}{c}2(2.6- \\
1.3)\end{array}$ & 6 \\
\hline i8. & Hazardous industries & 2 & $3(>1)$ & 6 & $1(0)$ & 2 \\
\hline i9. & Protected areas & 1 & $2(10-50 \%)$ & 2 & $1(10-50 \%)$ & 1 \\
\hline $\mathrm{i} 10$. & Water bodies & 1 & $2(10-50 \%)$ & 2 & $1(<10 \%)$ & 1 \\
\hline i11. & $\begin{array}{l}\text { Information/awareness } \\
\text { campaigns for the population }\end{array}$ & 3 & 1 (in 2016) & 3 & 1 (in 2016) & 3 \\
\hline i12. & $\begin{array}{l}\text { Training activities (exercises, } \\
\text { simulations) }\end{array}$ & 3 & 1 (in 2016) & 3 & 1 (in 2016) & 3 \\
\hline i13. & $\begin{array}{l}\text { Population alarm systems } \\
\text { coverage }\end{array}$ & 3 & $1(>50 \%)$ & 3 & $1(>50 \%)$ & 3 \\
\hline i14. & $\begin{array}{l}\text { Existence of emergency } \\
\text { shelters correlated to the } \\
\text { number of population }\end{array}$ & 3 & $3(<20 \%)$ & 9 & $3(<20 \%)$ & 9 \\
\hline $\mathrm{i} 15$. & $\begin{array}{l}\text { Existence of special CBRN } \\
\text { intervention teams }\end{array}$ & 3 & $\begin{array}{l}1 \text { (public and } \\
\text { private) }\end{array}$ & 3 & $\begin{array}{c}1 \text { (public } \\
\text { and private) }\end{array}$ & 3 \\
\hline i16. & $\begin{array}{lr}\text { Population } & \text { endowment with } \\
\text { individual } & \text { protection } \\
\text { equipment } & \\
\end{array}$ & 3 & $3(<20 \%)$ & 9 & $3(<20 \%)$ & 9 \\
\hline \multicolumn{3}{|c|}{ Total vulnerability } & \multicolumn{2}{|l|}{4.8} & \multicolumn{2}{|c|}{4.3} \\
\hline
\end{tabular}

Furthermore, these general campaigns are doubled by training activities, developed on a regularly basis, for both the employees of the studied Seveso establishment, as well as for the population outside the manifestation area. The result is an informed and trained population, able to respond in an adequate manner to emergency situations, which can be of significant importance in case of toxic dispersion, as the entire town population may be affected by its consequences. In case of ammonium nitrate explosion, it is more important for the employees on the site to know the adequate measures to be taken in order to protect themselves and their colleagues.

The coverage with alarm systems is very high (246\%), thus reducing the vulnerability degree, especially in case of toxic dispersion, when the early warning of the population may reduce the number of victims. These alarms are installed on the main buildings in the residential areas, as well as on the main industrial facilities in the affected area. In case of toxic dispersion, it is recommended to evacuate the surrounding area situated in wind direction; therefore, the existence of alarms systems is very important for saving human lives. If the population must remain inside the buildings, they should close the windows, to 
ensure the sealing of the buildings and to unplug the electrical devices, in order to prevent a fire. The alarm system covers also the studied Seveso establishment, allowing the rapid warning of the employees and of the surrounding population (especially the visitors of the city mall located across the site).

On the other hand, there are two indicators that contribute to the increase of the vulnerability level: the poor capacity of emergency shelters related to the number of population $(5 \%)$ and the lack of population endowment with individual protection equipment $(0 \%)$. For example, for the toxic dispersion of ammonia, hands, skin and eyes should be protected by using personal protective equipment, such as gloves, air-proof safety goggles, dust-proof suit, and safety footwear. The lack of protective equipment increases the risk of injuries for the city population: headaches, cough and breathing difficulties, eye injuries. The employees can use the protective equipment available on site. In Târgu-Mureș, there are special CBRN intervention teams at the County Inspectorate for Emergency Situations and within private industrial facilities (Seveso establishments). The existence of these intervention teams reduces vulnerability, the intervention in case of chemical accident being much more rapid and efficient. The CBRN intervention team on site includes the adequate means and equipment necessary for a rapid intervention, as well as trained personnel.

\section{CONCLUSIONS}

Considering that the analyzed case study is one of the major Seveso establishments in Romania, vulnerability reduction measures are necessary. For both scenarios it is proposed to improve traffic lines (for more efficient evacuation) and allocation of medical services, and include vulnerability assessment in land-use planning to reduce future risks.

Moreover, in the case of the first scenario (toxic dispersion), better sealing of windows and doors would be recommended, together with clear instructions for population evacuation and special care requirements for vulnerable groups (children and elderly people). To slow down the toxic cloud, vegetation barriers would be necessary around the water bodies.

In the second scenario (explosion), considering the proximity of the shopping mall (a few hundred meters), very strict safety measures, continuous monitoring and rigorous training of the personnel are required throughout the entire area of the industrial site.

In order to protect the population of the city and reduce the number of victims, it is necessary to build new shelters or improve the existing ones, to ensure a perfect sealing from the outside atmosphere. Furthermore, it is recommended to endow the exposed population with individual protective equipment, increasing the individual protection level and, thus, reducing the overall vulnerability.

\section{ACKNOWLEDGMENT}

This paper was supported by the European Social Fund, Administrative Capacity Operational Programme (POCA) SIPOCA grant 30, Disaster Risk Assessment at national level - RoRISK.

\section{R E F E R E N C E S}

Adger, W.N., Brooks, N., Bentham, G., Agnew, M. \& Eriksen, S., (2004) New Indicators of Vulnerability and Adaptive Capacity. Technical Report 7, Tyndall Centre for Climate Change Research, University of East Anglia, Norwich. 
Armaș, I. \& Gavriș, A., (2016) Census-based social vulnerability assessment for Bucharest. Procedia Environmental Sciences, 32, 138 - 146.

Botezan, C., Ozunu, Al. \& Ştefănie, H., (2015) Vulnerability Assessment: the Case of the Aries River Middle Basin, Journal of Environmental Protection and Ecology, vol. 16, no. 4, 1316 - 1326.

Campedel, M., (2008), Analysis of major industrial accidents triggered by natural events reported in the principal available chemical accident database. JRC Scientific and Technical Report, $38 \mathrm{pp}$.

Cardona, O.D., van Aalst, M.K., Birkmann, J., Fordham, M., McGregor, G., Perez, R., Pulwarty, R.S., Schipper E.L.F. \& Sinh, B.T. (2012) Determinants of risk: exposure and vulnerability. In: Managing the Risks of Extreme Events and Disasters to Advance Climate Change Adaptation. A Special Report of Working Groups I and II of the Intergovernmental Panel on Climate Change (IPCC). Cambridge University Press, Cambridge, UK, and New York, NY, USA, pp. 65-108.

Christou, M., Gyenes, Z. \& Struckl, M., (2011) Risk assessment in support to land-use planning in Europe: Towards more consistent decisions?, Journal of Loss Prevention in the Process Industries, 24, 219-226.

Chuanglin, F. \& Yan, W., (2016) A comprehensive assessment of urban vulnerability and its spatial differentiation in China. Journal of Geographical Sciences, 26(2): 153-170.

Constantin, V., Ștefănescu, L. \& Kantor, C.M., (2015) Vulnerability assessment methodology: A tool for policy makers in drafting a sustainable development strategy of rural mining settlements in the Apuseni Mountains, Romania. Environmental Science \& Policy, 52, 129-139.

Cozzani, V., Bandini, R., Basta, C \& Christou, M.D., (2006) Application of land-use planning criteria for the control of major accident hazards: A case-study, J. Hazard. Mater., A136, 170-180.

Cutter, S.L., Ash, K.D. \& Emrich, C.T., (2014) The geographies of community disaster resilience, Global Environmental Change, 29, 65-77.

Das, A., Gupta, A.K., Mazumdera, T.N., (2012) Vulnerability assessment using hazard potency for regions generating industrial hazardous waste. Journal of Hazardous Materials, 209- 210, 308317, doi:10.1016/j.jhazmat.2012.01.025.

Fedeski, M., Gwilliam, J., (2007) Urban sustainability in the presence of flood and geological hazards: The development of a GIS-based vulnerability and risk assessment methodology, Landscape and Urban Planning, 83, 50-61, doi:10.1016/j.landurbplan.2007.05.012.

Karashima, K., Ohgai, A. \& Saito, Y., (2014) A GIS-based Support Tool for Exploring Land Use Policy Considering Future Depopulation and Urban Vulnerability to Natural Disasters - A Case Study of Toyohashi City, Japan, Procedia Environmental Sciences. 22 ( 2014 ) 148 - 155.

Knox, P.L., (1980) Measures of accessibility as social indicators: A note. Social Indicators Research 7(1-4), 367-377, DOI 10.1007/BF00305607.

Lee, Y.-J., (2014) Social vulnerability indicators as a sustainable planning tool, Environmental Impact Assessment Review, 44, 31-42.

Li, F.Y., Bi, J., Huang, L., Qu, C.S., Yang, J. \& Bu, Q.M., (2010) Mapping human vulnerability to chemical accidents in the vicinity of chemical industry parks, J. Hazard. Mater.. 179, 500-506, doi:10.1016/j.jhazmat.2010.03.031.

Liverman, D. M., (1986) The vulnerability of urban areas to technological risks: An overview of US and European experience, Cities, Volume 3, Issue 2, Pages 142-147.

Plummer, R., de Grosbois, D., Armitage, D. \& de Loe, R.C., (2013) An integrative assessment of water vulnerability in First Nation communities in Southern Ontario, Canada. Global Environmental Change, 23, 749-763, doi:10.1016/j.gloenvcha.2013.03.005.

Ruffi, M.G., Piegau F. \& Monnani G., (2017) Natech risk analysis in "Seveso" plants, AES Bioflux Advances in Environmental Sciences - International Journal of the Bioflux Society 9(1): 77-91.

Smith, K., (1992), Environmental Hazards: Assessing and Reducing Disaster. Routledge, London.

Török, Z., Ajtai, N., Turcu, A.-T. \& Ozunu, A., (2011) Comparative consequence analysis of the BLEVE phenomena in the context on Land Use Planning; Case study: The Feyzin accident. Process Safety and Environmental Protection, 89, 1-7, doi:10.1016/j.psep.2010.08.003.

Zabeo, A., Pizzol, L., Agostini, P., Critto, A., Giove, S. \& Marcomini, A., (2011) Regional risk assessment for contaminated sites Part 1: Vulnerability assessment by multicriteria decision analysis. Environment International. 37, 1295-1306, doi:10.1016/j.envint.2011.05.005. 